\title{
A case of spinal anesthesia in a patient with progressive supranuclear palsy
}

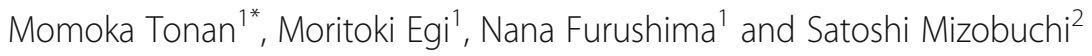

\begin{abstract}
Progressive supranuclear palsy (PSP) is one of the rare diseases. PSP is characterized by oculomotor dysfunction, postural instability, akinesia, dysarthria, and dysphagia. The major cause of death in patients with PSP is aspiration pneumonia. Considering these complications, spinal anesthesia is useful in patients with PSP. However, the potential harmful effects of spinal anesthesia including neurotoxicity of local anesthetics and neurologic complications for patients with PSP are unclear, because there has been no report. Here, we present spinal anesthesia for a patient with PSP. An 80-year-old man with progressive oculomotor dysfunction, dysphagia, and history of repeated aspiration pneumonia was scheduled for inguinal hernia surgery. Acutely concerning about perioperative pulmonary complications, we performed spinal anesthesia. Fortunately, there was no complication associated with respiration or neural system during perioperative period. We hope our experience and case report will be helpful in specific perioperative anesthetic care for patients with PSP.
\end{abstract}

Keywords: Progressive supranuclear palsy, Spinal anesthesia, Complication

\section{Background}

Progressive supranuclear palsy (PSP) is a rare disease with a prevalence of $5.8-6.5$ per 100,000 [1]. PSP is a progressing degenerative disease that is suspected to be related to tauopathies; however, its pathophysiology is still uncertain [2]. PSP is characterized by oculomotor dysfunction, postural instability, akinesia, dysarthria, and dysphagia [3]. It has been reported that the major cause of death in patients with PSP is aspiration pneumonia [4]. Considering the complications, spinal anesthesia is useful in patients with PSP. However, there is concern about the potential harmful effects of spinal anesthesia including neurotoxicity of local anesthetics and neurologic complications for patients with central nervous system disorder [5]. In this regard, the safety of spinal anesthesia for patients with PSP should be evaluated. However, there has been no report concerning spinal anesthesia in patients with PSP. Accordingly, we report a patient with PSP who had an operation for an inguinal hernia performed under spinal anesthesia.

\footnotetext{
* Correspondence: momokat5@gmail.com

${ }^{1}$ Department of Anesthesiology, Kobe University Hospital, 7-5-2, Kusunoki-cho, chuo-ku, Kobe, Hyogo 650-0017, Japan

Full list of author information is available at the end of the article
}

\section{Case presentation}

An 80-year-old man, $64 \mathrm{~kg}$ in weight and $166 \mathrm{~cm}$ in height, was scheduled for inguinal hernia surgery. He had been diagnosed with PSP 3 years before the operation based on progressive dysbasia, dysphagia and oculomotor dysfunction. Other medical history was hypertension requiring enalapril. He had received a partial pharyngectomy for middle pharynx cancer 5 years before the operation. His symptoms of PSP included weakness of coughing, mild cervical backward postural instability, dysphemia, and parkinsonism. He had mild cervical backward contracture. Dementia was not observed. Aspiration pneumonia had occurred once every few months, and his surgery had been repeatedly postponed. Suction of phlegm was needed every $2-3 \mathrm{~h}$ daily. Despite repeated aspiration pneumonia, preoperative chest radiography showed no consolidation, and the results of a respiratory function test showed $1.9 \mathrm{~L}$ of forced expiratory capacity (FEV1.0) and $79.6 \%$ of vital capacity (\%VC). The results of electrocardiography and a blood examination were normal.

We decided to perform spinal anesthesia combined with epidural anesthesia for the patient. An epidural catheter was inserted $5 \mathrm{~cm}$ through Th12/L1. Spinal anesthesia was performed using $2.8 \mathrm{~mL}$ of $0.5 \%$ 
hyperbaric bupivacaine through L3/4. Surgery was started after confirming Th4 level of anesthesia by pinprick. During the surgery, the attending physician sucked secretion to eliminate oral retention in order to prevent aspiration pneumonia. The patient's oxygen saturation was preserved at around 95\% without any oxygen administration. The surgery was completed after 125 min without any complications. Swallowing function was checked $10 \mathrm{~h}$ later and oral intake was started on postoperative day 1 (POD 1). We confirmed that postoperative analgesia was sufficient only with acetaminophen administration on POD 1, and we stopped epidural anesthesia on POD 1. On POD 6, he was discharged from the hospital without aspiration pneumonia, exacerbation of neurological symptoms or any other complications.

\section{Discussion}

For consideration of the anesthetic management for this case, we performed a literature search to find reports on anesthetic management in patients with PSP. We found seven case reports [6-12] (Table 1). There was no report on spinal anesthesia for a patient with PSP. Although the information in these reports and the results of our experiments are limited for drawing a conclusion, some anesthetic considerations could be obtained.

First, consideration should be given to the prevention of perioperative aspiration pneumonia. Takahashi et al. [11] reported that a patient with PSP after gastric surgery under general and epidural anesthesia had postoperative pneumonia. Progressive dysphasia and weakness of sputum excretion seen in patients with PSP would increase the risk of aspiration pneumonia. In this case, a history of partial pharyngectomy may worsen the symptoms of dysphasia in addition to those related to PSP. It has been reported that general anesthesia may increase the risk of postoperative pulmonary complications compared with regional anesthesia [13]. Arozullah et al. showed that the odds ratio of patients undergoing major non-cardiac surgery using general anesthesia was 1.56 (confidence interval, 1.36 to 1.80$)$ compared with patients receiving local anesthesia [14]. Canet et al. [15] also reported that the risk for postoperative pulmonary complications with general anesthesia was 3.7-times higher than that with regional anesthesia. Thus, regional anesthesia seems to be effective for preventing aspiration pneumonia. However, it should be noted that regional anesthesia is relatively safe but not absolutely safe. Accordingly, we did not use any sedative agents and opiates, and secretion was sucked to eliminate oral retention during the operation.

Second, cervical dystonia may cause difficulties in airway management. Sakai et al. [6] have reported that awake orotracheal intubation was impossible for a patient with PSP because of strong airway stenosis caused by cervical backward tile and neck contracture. Maggi et al. [7] also reported difficulty in fitting on laryngeal airway mask in patients with PSP. Considering the awake orotracheal intubation reported by Sakai et al., it is possible that muscle relaxant was able to be used safety because sugamadex is available in Japan. Nonetheless, physicians should note the possibility of a difficult airway in patients with PSP.

The above two considerations related to the risk of pulmonary complications and management regional anesthesia may be preferable for patients with PSP, if appropriate. However, Lirk et al. [16] reported that regional anesthesia may be a risk for patients with pre-existing neuropathy such as diabetic peripheral neuropathy, multiple sclerosis, and Guillain-Barre syndrome. They suspected that spinal anesthesia may cause neuronal ischemia [17] or infarction owing to changes in endoneurial small vessels, blocking of sodium channels in demyelinated areas or interaction of regional anesthesia with peripheral myelin or nerve trauma, which may result in deterioration of symptoms. Accordingly, they suggested that spinal anesthesia should be avoided if there are safe alternatives in patients with pre-existing neuropathy. It should be noted that it is not clear whether spinal anesthesia for patients with PSP is safe since there has been no report for this scenario. In contrast to Lirk's

Table 1 Summary of case reports for anesthetic management in patients with progressive supranuclear palsy

\begin{tabular}{|c|c|c|c|c|c|c|c|}
\hline Journal & Year & Age & Sex & Type of surgery & Maintenance anesthesia & Perioperative complications & Reference \\
\hline J Anesth & 2006 & 74 & $\mathrm{~F}$ & Laryngotracheal separation & General & Difficulty of awake intubation & {$[6]$} \\
\hline $\begin{array}{l}\text { Acta Anaesthesiol } \\
\text { Taiwan }\end{array}$ & 2012 & 81 & $\mathrm{~F}$ & $\begin{array}{l}\text { Mammary tumor extirpation, } \\
\text { ipsilateral lymph node excision }\end{array}$ & General & Difficulty of LMA fitting & {$[7]$} \\
\hline $\begin{array}{l}\text { Acta Anaesthesiol } \\
\text { Taiwan. }\end{array}$ & 2013 & 70 & M & Above-knee amputation & General & - & {$[8]$} \\
\hline J Clin Anesth & 1987 & 72 & $\mathrm{~F}$ & Mammary tumor extirpation & Epidural & - & [9] \\
\hline J Jpn Surg Assoc & 1997 & 68 & M & Sigmoid colon resection & Epidural + sevoflurane & $\begin{array}{l}\text { Aagitation, needed nasal airway, } \\
\text { abdominal rigidity during surgery }\end{array}$ & {$[10]$} \\
\hline Jpn J Anesth & 2010 & 60 & $\mathrm{~F}$ & Left cataract, right graucoma surgery & General & - & {$[11]$} \\
\hline J Clin Anesth & 2012 & 72 & M & Gastrectomy & General + epidural & $\begin{array}{l}\text { Delayed emergence, postoperative } \\
\text { pneumonia }\end{array}$ & {$[12]$} \\
\hline
\end{tabular}


suggestion, Hebl et al. [18] reported that there were no new or deteriorating neurologic complications after neuraxial anesthesia, though technical complications occurred in $11 \%$ of the patients.

Our patient had considerable oral secretion and residual sputum with repeated aspiration pneumonia. $\mathrm{He}$ also had cervical backward contracture. Considering the balance of pulmonary and airway complications related to general anesthesia and the uncertain risk of progression of neural disorders, we decided to perform spinal anesthesia in our patient. We also inserted on epidural catheter to provide epidural anesthesia in case of prolonged surgery and for postoperative analgesia. The operation was performed without any trouble and the patient was discharged from hospital without any postoperative pneumonia or neurological complications. Nonetheless, taking into account the possibility of neurotoxicity of local anesthetics, a continuous peripheral nerve block with a percutaneously inserted catheter would be good alternative option for patients with PSP.

\section{Conclusions}

In summary, we experienced spinal anesthesia for a patient with PSP. We hope our case report and experience will shed light on specific considerations in perioperative care for patients with PSP.

\section{Abbreviations}

FEV: Forced expiratory capacity; POD: Postoperative day; PSP: Progressive supranuclear palsy; VC: Vital capacity

\section{Authors' contributions}

MT collected the information and wrote the draft. ME, NF, and MS revised and supported to write the final draft. All authors read and approved the manuscript for submission.

\section{Consent for publication}

For this case report, the consent to publish was obtained from the patient.

\section{Competing interests}

The authors declare that they have no competing interests.

\section{Publisher's Note}

Springer Nature remains neutral with regard to jurisdictional claims in published maps and institutional affiliations.

\section{Author details}

'Department of Anesthesiology, Kobe University Hospital, 7-5-2, Kusunoki-cho, chuo-ku, Kobe, Hyogo 650-0017, Japan. ${ }^{2}$ Division of Anesthesiology, Department of Surgery Related, Kobe University Graduate School of Medicine, 7-5-2, Kusunoki-cho, chuo-ku, Kobe, Hyogo 650-0017, Japan.

Received: 13 December 2017 Accepted: 17 January 2018 Published online: 25 January 2018

\section{References}

1. Ling H. Clinical approach to progressive supranuclear palsy. J Mov Disord. 2016;9:3-13

2. Rampello L, Buttà V, Raffaele R, Vecchio I, Battaglia G, Cormaci G, et al. Progressive supranuclear palsy: a systematic review. Neurobiol Dis. 2005:20:179-86.
3. Respondek G, Kurz C, Arzberger T, Compta Y, Englund E, Ferguson LW, et al. Which ante mortem clinical features predict progressive supranuclear palsy pathology? Mov Disord. 2017;32:995-1005.

4. Nath U, Thomson R, Wood R, Ben-Shlomo Y, Lees A, Rooney C, et al. Population based mortality and quality of death certification in progressive supranuclear palsy (Steele-Richardson- Olszewski syndrome). J Neurol Neurosurg Psychiatry. 2005;76:498-502.

5. Tseng WC, Wu ZF, Liaw WJ, Hwa SY, Hung NK. A patient with postpolio syndrome developed cauda equina syndrome after neuraxial anesthesia. A case report. J Clin Anesth. 2017;37:49-51.

6. Sakai K, Sumikawa K. Anesthetic management of a patient with progressive supranuclear palsy. J Anesth. 2006;20:312-3.

7. Maggi G, Schiraldi R, Brogly N, Arevalo EG, Rodriguez FG. Successful airway management of a patient with progressive supranuclear palsy during the induction of anesthesia. Acta Anaesthesiol Taiwanica. 2012;50:87-8.

8. Shimizu S, Kawashima S, Seo K. Anesthetic management of above-knee amputation in a patient with progressive supranuclear palsy. Acta Anaesthesiol Taiwanica. 2013; https://doi.org/10.1016/j.aat.2013.03.005.

9. Tanaka K, Yokota M, Asayama Y, Tsukada Y, Inoue D, Yoshizawa A, et al. An anesthetic case of a patient with progressive supranuclear palsy. J Clin Anesth. 1987;11:906-8.

10. Mukai N, Tsutsumi N, Satoh S, Hidaka K, Miyazaki K. Sigmoid colon cancer associated with progressive supranuclear palsy. J Jpn Surg Assoc. 1997:58:855-9.

11. Takahashi S, Okada R, Goto T. An anesthetic case of a patient with supranuclear palsy. J Clin Anesth. 2012;36:791-2.

12. Takano E, Serita R, Hotta M, Yumura J, Ouchi T, Koitbashi T. An anesthetic case of a patient with multiple sclerosis and supranuclear palsy. Jpn J Anesth. 2010;59:906-10

13. Miskovic A, Lumb AB. Postoperative pulmonary complications. Br J Anaesth. 2017:118:317-34.

14. Arozullah AM, Khuri SF, Henderson WG, Daley J. Development and validation of a multifactorial risk index for predicting postoperative pneumonia after major noncardiac surgery. Ann Intern Med. 2001;135:847-57.

15. Canet J, Gallart L, Gomar C, Paluzie G, Vallès J, Castillo J, et al. Prediction of postoperative pulmonary complications in a population-based surgical cohort. Anesthesiology. 2010:113:1338-50.

16. Lirk P, Birmingham B, Hogan Q. Regional anesthesia in patients with preexisting neuropathy. Int Anesthesiol Clin. 2011:49:144-65.

17. Hirose N, Kondo Y, Maeda T, Suzuki T, Yoshino A. Relationship between regional cerebral blood volume and oxygenation and blood pressure during spinal anesthesia in women undergoing cesarean section. J Anesth. 2016:30:603-9.

18. Hebl JR, Horlocker TT, Schroeder DR. Neuraxial anesthesia and analgesia in patients with preexisting central nervous system disorders. Anesth Analg. 2006;103:223-8.

\section{Submit your manuscript to a SpringerOpen ${ }^{\circ}$ journal and benefit from:}

- Convenient online submission

Rigorous peer review

- Open access: articles freely available online

- High visibility within the field

- Retaining the copyright to your article

Submit your next manuscript at $>$ springeropen.com 